\title{
Contribución del pensamiento amerindio a una cosmopolítica americana
}

\author{
Contribution of Amerindian Thought to American Cosmopolitics
}

Contribuição do pensamento ameríndio para uma cosmopolítica americana

\section{Juan Duchesne Winter}

UNIVERSITY OF PITTSBURGH, ESTADOS UNIDOS

Profesor de Literatura Latinoamericana en la Universidad de Pittsburgh.

$\mathrm{PhD}$, State University of New York-Stony Brook. Autor de $L a$ guerrilla narrada. Acción, acontecimiento, sujeto (Editorial Callejón, 2010); Comunismo literario y teorías deseantes: inscripciones latinoamericanas (Plural, 2009), Del príncipe moderno al señor barroco: la república de la amistad en Paradiso, de fosé Lezama Lima (Archivos del Índice, 2008), Equilibrio encimita del infierno: Andrés Caicedo y las utopías del trance (Archivos del Índice, 2007), Fugas incomunistas (San Juan, 2005), Ciudadano insano (Editorial Callejón, 2001), Política de la caricia (Editorial Nómada, 1996), Narraciones de testimonio en América Latina (Editorial de la Universidad de Puerto Rico, 1991). Correo electrónico: duchesne@pitt.edu

\footnotetext{
Artículo de reflexión

Esta es la versión escrita de una alocución pronunciada en el Encuentro de Pensamiento Latinoamericano, en el marco del Festival de la Palabra, celebrado en Tecnópolis, Buenos Aires, en abril de 2014. A estas condiciones responde su formato de ensayo-discurso, diferente del artículo académico como tal. Este ensayo se desprende del Proyecto Cosmopolíticas Amerindias, financiada desde el año 2010, por el Center for Latin American Studies, University of Pittsburgh, Estados Unidos. Documento accesible en línea desde la siguiente dirección: http://revistas.javeriana.edu.co

doi: 10.11144/Javeriana.cl19-38.cpac
} 


\section{Resumen}

El extractivismo como proceso de saqueo irreparable de la naturaleza ha llegado a sus límites. El pensamiento animista amerindio, en especial amazónico, postula ontologías de la actividad vital colectiva que ofrecen alternativas a la ley del valor y a sus corolarios del productivismo y la acumulación infinita, consustanciales a la civilización moderno-capiltalista.

Palabras clave: extractivismo; indígenas suramericanos; América del Sur; Marc de Civrieux; capitalismo

\section{Abstract}

Extractivism has reached its limits as an irreparable process of sacking nature. Amerindian animistic thought, especially that of the Amazon, postulates ontologies of collective vital activity that offer alternatives to the law of value and its corollaries of productivism and endless accumulation, consubstantial to moderncapitalist civilization.

Keywords: extractivism; SouthAmerican indigenous peoples; South America; Marc de Civreieux; capitalism

\section{Resumo}

O extrativismo como processo de espoliação irreparável da natureza chegou aos seus limites. $\mathrm{O}$ pensamento animista ameríndio, em especial o amazónico, postula ontologias da atividade vital coletiva que oferecem alternativas à lei do valor e seus corolários do produtivismo e a acumulação infinita, consubstanciais à civilização moderno-capitalista.

Palavras-chave: extrativismo; indígenas sul-americanos; América do Sul; Marc de Civrieux; capitalismo

RECIBIDO: 17 DE OCTUBRE DE 2014. ACEPTADO: 23 DE NOVIEMBRE DE 2014. DISPONIBLE EN LÍNEA: 1 DE JULIO DE 2015

\section{Cómo citar este artículo:}

Duchesne Winter, Juan. "Contribución del pensamiento amerindio a una cosmopolítica americana". Cuadernos de Literatura 19.38 (2015): 269-278. http://dx.doi.org/10.11144/Javeriana.cl19-38.cpac 
Desde la conquista europea América ha sido pensada y tratada como una tierra de extracción. Y esa verdad continúa intacta todavía. América, específicamente Sudamérica, es todavía una tierra de extracción, en casi los mismos términos estructurales que durante la colonia. Advirtamos que la extracción, tal cual aquí usamos el concepto, no consiste en tomar de la tierra lo que se necesita, es tomar más bien lo que no se necesita sino en función de un ciclo global de acumulación de valor abstracto, en el sentido definido por Marx. En años recientes la fiebre extractora ha aumentado:

América Latina se ha constituido en el destino más importante de la inversión minera en el mundo. A comienzos de la década del noventa la región captaba el 12\% de la inversión minera mundial y a comienzos de la actual había casi triplicado ese flujo, captando el 33\%". (Observatorio Latinoamericano de Conflictos Ambientales, OLCA 2013)

Tanto los Estados latinoamericanos caracterizados como neoliberales como aquellos autodenominados como progresistas o aun socialistas, participan de la misma estructura de extracción en función de la circulación global del capital, regida por las corporaciones transnacionales, el control, represión, expropiación y desplazamiento de las comunidades directamente afectadas, y la destrucción de agriculturas autosostenibles, hábitats naturales, fuentes de agua y alteración y mutilación imprevisible, vía la toxicidad, de los recursos genéticos de múltiples especies, incluida la humana. La mayor diferencia significativa entre los Estados latinoamericanos progresistas, nacional-populistas o socialistas y aquellos que no aspiran a ese rango es que en los primeros existen mecanismos de redistribución compensatoria mediante los cuales una fracción de la renta extractiva se dirige a la población visualizada como base electoral real o virtual, aunque no necesariamente se compensa a las comunidades más afectadas, sobre todo si estas no se traducen en grandes masas votantes. En cierta manera, el Estado compensatorio, cual lo define Eduardo Gudynas en "Estado compensador y nuevos extractivismos" (2012), convierte a las bases electorales de la población que reciben una mínima pero concreta compensación por vía de inversiones sociales asistencialistas y caritativas, en aliados del sistema de extracción del cual se obtienen esas compensaciones. Ante la disminución sistémica, históricamente irreversible del trabajo como componente orgánico del capital y el desempleo crónico, surgen grandes masas dependientes de las prestaciones del Estado extractor. Obtenemos entonces, como respuesta cortoplacista una suerte de "populismo extractivista" fundado sobre la renta de la extracción de la tierra, ejemplo extremo del cual lo provee el Estado venezolano actual, si bien Colombia, Ecuador, Perú, Bolivia, Chile y Argentina se aproximan tendencialmente en esa dirección. 
Se trata de una respuesta con beneficios a relativamente corto plazo, dada la persistencia de las mismas condiciones de intercambio desigual que mantienen a los países proveedores de materias primas en esa llamada "periferia" creada por relaciones de "dependencia" que ya los estudiosos de las estructuras neocoloniales en los mercados globales definieron hace décadas. Como dice Gudynas, basándose en Fernando Coronil (El Estado mágico), se ha demostrado que "allí donde los ingresos dependen de la mercantilización de la naturaleza, la captura de la renta condiciona la organización de las actividades económicas y del Estado" (Gudynas 140). Por estas razones, la relación desigual reproducida por el extractivismo no conduce al tipo de socialdemocracia que se ha establecido en determinados países europeos que no están sujetos al intercambio desigual. Más bien se crea un círculo vicioso en el que la entrega de recursos naturales a las transnacionales extractivas desplaza mayores poblaciones, destruye medios autónomos de vida y lanza mayores sectores al desempleo y la dependencia de las prestaciones benéficas del Estado, que a su vez depende cada vez más de la renta extractivista (Gudynas 144-145).

Es hora de pensar a América Latina como una gran colectividad de actores que no tienen por qué regirse según la gran barrera entre la naturaleza y la sociedad desarrollada por el antropocentrismo moderno. América Latina no tiene por qué reducirse a una tierra de extracción donde el humano se concibe como el actor único frente a la multitud de entes supuestamente pasivos llamados naturaleza que yacen inermes a su disposición. La faena delirante de extracción de hidrocarburos, la minería destructiva de fuentes de agua y de alimentos, las agroindustrias concebidas como minería (tales como la soja, la palma de aceite, los agro-combustibles), la consecuente intoxicación generalizada de tierras, ríos, lagos y mares, y el exterminio de la diversidad de cosechas mediante siembras transgénicas, todo ello redundará según ya demostró la ciencia, en la desestabilización y aniquilación de la biosfera, la ruptura irreversible de la delicada retícula de la vida en el planeta.

La biosfera es un sistema de retroalimentación negativa que aguanta muchos impactos. Pero este sistema pertenece a su vez a otros sistemas geológicos, atmosféricos, químicos que tienen sus propias dinámicas, no siempre de retroalimentación negativa, sino también de retroalimentación positiva y aceleración geométrica. Los humanos no pueden en efecto, destruir la naturaleza, pues no solo son parte de esta, sino que sus propias tecnologías destructivas son parte de las fuerzas naturales. Más bien la naturaleza puede sin duda, destruir al humano, que es meramente uno de sus entes. Las emisiones de carbono son una fuerza natural. Los transgénicos que mutilan los genomas vegetales y humanos también 
son actores naturales. No hay un afuera de la naturaleza. Tampoco hay tal cosa como una Madre Naturaleza; la naturaleza no es madre de nadie, ni tiene por qué proteger a nadie, acaso es madrastra de ella misma. Los minerales, las capas tectónicas, las combustiones químicas del planeta y de las estrellas protagonizan ciclos y procesos entre los cuales las formas de vida orgánica que conocemos, incluida la humana, son un objeto más entre miles de millones. Una vez sobrepasado un umbral imposible de determinar, pero ciertamente real e inminente, las tecnologías de intoxicación y destrucción de formas y hábitats de vida, que también son ellas mismas fuerzas naturales, se combinarán con procesos geológicos y químicos para catalizar otras fases dinámicas completamente ajenas a las condiciones de reproducción de la vida humana y las miles de especies orgánicas interdependientes que articulan la biosfera, para inaugurar tranquilamente otros ciclos donde para nada es necesaria la preservación de los actores humanos ni sus tecnologías. Lo que se ha llamado el antropoceno, en el sentido en que la biosfera es producto de procesos centrados en torno a la actividad de los homínidos, muy bien puede conducir a la era de la antropolisis, de disolución bioquímica de los actores homínidos.

Durante la Guerra Fría la lógica de la destrucción mutua y bilateral asegurada, es decir, la conciencia de la inminencia de la catástrofe atómica, sirvió como estímulo muy real a la contención de la catástrofe. Se ha sugerido que en el siglo XXI, la lógica de la autodestrucción ecológica multilateral asegurada podría cumplir una función similar, lo que conllevaría una "ética de la catástrofe", como propone Jean-Pierre Dupuy en Pour une catastrophisme éclairé (2002). Existen maneras de reforzar la retroalimentación negativa de la biosfera de tal manera que esta no salte a los ciclos de retroalimentación positiva acelerada que implican la devastación de la vida humana. Los enfoques alternativos al antropocentrismo moderno implican grandes transformaciones no solo en las relaciones interhumanas, es decir, sociales en el sentido convencional, sino en las relaciones entre humanos y no humanos, en un sentido cósmico.

Entre los pensadores más alertas de nuestro tiempo hay quienes proponen sustituir el actual antropocentrismo moderno por una cosmopolítica. La cosmopolítica de la cual hablamos aquí repudia la gran barrera entre la naturaleza y la cultura erigida por el antropocentrismo moderno occidental. Se propone que no hay tal cosa como una sociedad y cultura humana que de alguna manera se erija en contraposición a la naturaleza, pretendiéndose ubicar todo lo que sea percepción, afecto, reflexión, agencia, y voluntad exclusivamente en el homo sapiens, otorgándose al resto de las entidades de la naturaleza, a lo sumo, una capacidad de actividad mecánica enteramente programada y programable que redunda en su 
eventual postración ante los designios humanos. Al rechazar tal concepción antropocéntrica, la cosmopolítica propone que las sociedades y culturas, incluida la moderna occidental, son subconjuntos de las colectividades naturales y que no hay tal cosa como sociedades o culturas exclusivamente humanas, sino colectividades mixtas, híbridas en que animales, plantas, microorganismos, minerales, entidades químicas, geológicas, atmosféricas, astronómicas; artefactos humanos, sistemas de signos y lenguajes, personas humanas, ideas, conceptos, afectos, interactúan en un mismo plano de agencia, si bien respondiendo a reglas autónomas, inconmensurables e irreductibles entre sí. Esta ontología cósmica recibe el sufijo de política y se denomina cosmopolítica precisamente porque no conlleva una reducción de los fenómenos y objetos políticos a la biología o las mecánicas físico-químicas, sino que más bien eleva los entes antes considerados al rango de actores que inciden en colectividades mixtas desde perspectivas igualmente singulares e irreductibles. No se trata entonces de reducir los objetos sociales, culturales, semióticos, lingüísticos y psíquicos a las leyes de la biología o la físico-química cual se pretende por ejemplo, desde cierto cientificismo estrecho, sino de validar las relaciones existentes entre entidades asociadas a todos los campos del cosmos como relaciones que implican una política humanista, una política que reconozca la agencia múltiple de actores humanos y no humanos a nivel cósmico, es decir, una cosmopraxis. Como vemos, esta política es antropomórfica mas no antropocéntrica, por eso es humanista de una manera más amplia: las cualidades humanas se diseminan en el cosmos mas no se centralizan exclusivamente en el homo sapiens, como bien ha explicado Eduardo Viveiros de Castro en La mirada del jaguar (2013).

La crisis del capitalismo global no tiene salida pues, en lo fundamental no responde, como suponen muchos, ni al imperialismo ni al neoliberalismo ni a la avaricia de los banqueros, ni a la financiarización, sino al proceso histórico irreversible de la reducción del trabajo en la composición orgánica del capital que se traduce y seguirá traduciéndose en tasas cada vez mayores de desempleo crónico (Moishe Postone). Todo señala que la sociedad del trabajo, entendido en el sentido capitalista-industrial de la producción de valor, ha empezado hace rato a colapsar irreversiblemente y no hay manera de recuperar aquellos tiempos de simbiosis entre el laborismo masivo y el fordismo explotador pero proveedor. Cada vez mayores sectores de la población, generaciones enteras, ya cada vez menos consignadas a las llamadas villas y favelas, hacen sus vidas fuera del trabajo ligado orgánicamente al ciclo de reproducción del capital. Las economías de extracción constituyen un intento por remediar esta situación, pero a pesar de sus éxitos a corto plazo, son inconducentes por reducirse al saqueo y la destrucción irreversible del potencial albergado por las pocas economías autosustentables 
que todavía no dependen enteramente del ciclo de valorización global del trabajo, sino de la acción cosmopolítica concertada entre actores del hábitat inmediato. El desplazamiento y la expropiación consustanciales a la gran minería corporativa (que desplaza a decenas de miles de personas que subsisten de la minería artesanal y la agricultura diversificada) generan todavía más desempleo y más favelas. Sólo una cosmopolítica puede sustentar la redefinición radical de lo que significa producir y vivir en el marco de relaciones autosustentables entre los actores humanos y no humanos de la biosfera y dar salida a esta crisis impuesta por las restricciones antropocéntricas de la ley capitalista del valor.

El pensamiento animista americano tal cual registrado en los pueblos amerindios de la Amazonía, la Orinoquia y otras tierras bajas de Sudamérica y según interpretado por importantes etnógrafos, ha contribuido enormemente al desarrollo de los enfoques cosmopolíticos. Pierre Clastres, Lévi-Strauss, Gilles Deleuze, Eduardo Viveiros de Castro y Bruno Latour han reconocido la gran influencia del pensamiento amerindio en sus teorías. El giro más importante que el animismo amerindio le ofrece al pensamiento cosmopolítico contemporáneo es su perspectiva decididamente antropomórfica y antropogénica (Viveiros de Castro; Philippe Descola). El animismo amerindio no es antropocéntrico, pero no por eso deja de insistir en prácticas muy intensas de humanización, por la vía del reconocimiento de la perspectiva humana como posicionalidad potencial universal asumible por múltiples entes humanos y no humanos, orgánicos y no orgánicos, materiales e inmateriales. Esto supone un correctivo a ciertos enfoques llamados posthumanistas, de origen anglo-germánico, inclinados a un antihumanismo, a mi juicio relativamente nihilista y restringido, en la medida en que solo enfatizan lo que consideran es la esencia no-humana, inclusive anti-humana del cosmos, desde un pretendido "materialismo duro" que en verdad supone una reducción del concepto de materia (ver Ray Brassier, Nihil Unbound. Enlightenment and Extinction).

El lenguaje y las artes verbales como la literatura son actores claves en el desarrollo de la cosmopolítica que requiere nuestro tiempo. Los vericuetos de la imaginación literaria son incatalogables y los temas y formas más diversos inciden por vías impredecibles en la cosmopraxis contemporánea. La fantasía y la imaginación en todas sus expresiones proveen el venero de plasticidad constructiva exigido por la cosmopraxis más allá de cualquier lectura ideológica o estética específica, pues la literatura reconoce en las propias palabras, en toda clase de personajes humanos y no humanos, el potencial de intervenir como actores singulares en la conformación de un mundo pleno. Ahora bien, si nos interesa hallar expresiones más o menos directas de los conceptos y nociones aquí vertidos, tenemos a nuestra disposición obras del legado literario americano tales como el 
Watunna. El Watunna es un ciclo de relatos originarios creado por los yekuana en la Orinoquia venezolana, en el cual se articula un pensamiento cosmopolítico muy vigente en nuestros tiempos. La matriz del Watunna consiste en un ciclo oral en la lengua so'to de la rama caribe hablada por los yekuana. Existe solo en la memoria colectiva y se ajusta constantemente a las experiencias y reflexiones del pueblo yekuana y de los individuos que lo conforman. Pero existe una traducción al español consignada a la escritura por el sabio franco-venezolano Marc de Civrieux. Aquí no podemos siquiera resumir los contenidos filosóficos del Watunna, pero sí podemos describir someramente la cosmopraxis de sus propias condiciones de enunciación para brindar una imagen concreta de la aportación amerindia a una posible cosmopolítica americana que nos sugiera otra cosa que las ruinas circulares de la extracción en las que giramos desde la conquista.

El discípulo de Marc de Civrieux y traductor del Watunna al inglés, David Guss cuenta que durante meses estuvo tratando de convencer a un amigo yekuana, Juan Castro, que le contara todo el Watunna. A pesar de la amistad que los unía, cada vez que Guss le pedía a Juan Castro que le contara el Watunna, este evadía el pedido, dando a entender que tal cosa no tenía sentido ni propósito. Finalmente Guss le dijo a Juan Castro que estaría dispuesto a aprender a hacer cestas con él, a lo que este accedió gustoso. Los hombres yekuana dedican tanto tiempo (o más) a la cestería como el que dedican a la cacería y la pesca. Guss se dio cuenta que la cestería sería una entrada apropiada al mundo del Watunna porque el gran ciclo de relatos es mucho más que un artefacto de arte verbal tal cual se lo entiende en la tradición moderna.

Se desprende de la actitud de Juan Castro que contar el Watunna por contarlo, como si fuera mero entretenimiento o satisfacción de una curiosidad, no tenía sentido, pero sí lo tenía si la gran obra verbal se articulaba al entramado de la cestería, dado que el Watunna se entrelaza con toda la actividad colectiva de los yekuana. Cada diseño de cestería representa, mediante abstracciones codificadas, a personajes y acciones claves del Watunna. Fabricar las cestas en el orden apropiado de manera que la articulación de las palabras se enhebre con la articulación de las fibras y el movimiento de las cuerdas vocales con el movimiento de las manos, es una de las maneras en que los yekuana, al recitar el Watunna, afirman sus vínculos con los seres supervitales de naturaleza vegetal-animal-humanaespiritual-sideral que conforman junto a ellos una colectividad animista cósmica. Asimismo todas las actividades de reproducción de los medios de existencia de los yekuana son indisociables de la recitación del Watunna, sea la cestería, la pesca, la caza, la horticultura, la artesanía, la construcción (de casas y canoas) y las relaciones familiares o comunales. 
La construcción y estructura toda de la gran casa comunal o maloca reproduce en cada una de sus formas la cosmografía del Watunna como espacio psíquicosocial integral. Cada vez que se realiza una actividad clave de reproducción de las condiciones de vivir, se materializa un episodio específico del Watunna que la conecta a toda la gesta colectiva acumulada desde el más remoto pasado hasta el presente. Cada actividad realizada cada hora del día reactiva y hace presentes en sus más mínimos detalles los vínculos cósmicos de la colectividad contenidos en el Watunna. El entramado de acontecimientos mítico-históricos que involucran a humanos y no-humanos, condensado en el Watunna y las actividades de la vida cotidiana que desde nuestra perspectiva podríamos llamar "producción", es tan íntimo que no se puede determinar si los yekuana trabajan para producir el Watunna o si recitan y cantan el Watunna para producir otros objetos de uso y consumo, pues todo se interconecta a modo de una retícula de multiplicidades indiscernibles. No hay manera de separar lo profano de lo sagrado ni lo práctico-material de lo ritual, espiritual o simbólico. Las tecnologías materiales son inseparables de las tecnologías espirituales. Las herramientas y los materiales de trabajo, de origen vegetal y mineral diverso no simplemente se manejan, en el sentido instrumental, pues involucran y requieren la comunicación con entidades invisibles inherentes a su esencia, mediante cantos y otras acciones rituales que constituyen también artefactos que remiten la tarea específica a realizarse a un entramado cósmico.

El hacedor yekuana debe participar en un diálogo metafísico con los artefactos y sus componentes vegetales y minerales con los cuales se involucra personalmente, reconociéndolos como actores singulares, exigencia que explica por qué muchos hombres yekuana y de otras sociedades similares asumen la actividad artesanal de la cestería como forma de meditación metafísica, más allá de la necesidad específica del implemento fabricado. El implemento físico se convierte así en un producto integrado a un flujo deseante. La producción deja de ser solamente producción de productos (i.e., bienes o valores particulares) y se aproxima además a lo que llamaríamos la producción de producción, es decir, al deseo. En fin, las propias condiciones de producción de una obra verbal como el Watunna remiten a una red de relaciones cosmopolíticas entre actores diversos de colectividades mixtas. Se demuestra cómo la actividad de hacer, expresarse y pensar, integradas a un tramado cosmopolítico, ayuda a elaborar otro sentido de la tierra mucho más rico y vital que el de la mera tierra de extracción.

Este modelo apunta, si bien muy parcialmente en las derivas de pensamiento a que da lugar, a la polis cósmica que podría realizar las urgentes tareas de restablecimiento de la sostenibilidad de la biosfera, no como tarea antropocéntricamente reductible, sino como tarea antropogénicamente expansible, en que el habitante 
humano no reduce el mundo de acuerdo a su medida, sino que amplía su existir de acuerdo a la medida del mundo y desarrolla aquellos potenciales cósmicos inevitablemente inherentes a su especie, que trascienden a la especie misma.

También apunta este modelo en fin, a un concepto ampliado de la "producción" que rebase la ley capitalista del valor y entrañe la necesaria procuración, creación recíproca, multívoca y multi-actorial de los medios, bienes y condiciones materiales y espirituales de la vida por colectividades humanas y transhumanas en sintonía con los ritmos naturales de retroalimentación negativa que más le convienen a una biosfera afín a nuestra óptima reproducción fisiológica y psíquica.

La aportación amerindia a la cosmopolita es eso, una aportación importante, tal vez imprescindible, pero no estamos hablando aquí de asumir las culturas, costumbres o cosmovisiones amerindias (que de por sí son plurales, heterogéneas y contradictorias cual todas) como sustituto de una "cultura occidental" supuestamente depositaria de todas las alienaciones malignas ni mucho menos, sino de reconocer en la perspectiva cosmopolita de deriva indígena un aspecto clave y prometedor del pensamiento y la sensibilidad de nuestra época.

\section{Obras citadas}

Brassiere, Ray. Nihil unbound. Enlightenment and extinction.

Nueva York: Palgrave Macmillan, 2007.

Civrieuex, Marc de. Watunna. Un ciclo de creación en el

Orinoco. Caracas: Monte Ávila Editores, 1992.

Coronil, Fernando. The Magical State: Nature, Money, and Modernity

in Venezuela. Chicago: University of Chicago Press, 1997.

Descola, Philippe. Beyond Nature and Culture. Chicago y

Londres; University of Chicago Press, 2013.

Dupuy,Jean-Pierre. Pour un catastrophisme éclairé. París: Éditions du Seuil, 2002.

Gudynas, Eduardo. "Estado compensador y nuevos extractivismos".

Nueva Sociedad 237 (enero-febrero 2012): 128-146.

Guss, David. To Weave and to Sing. Art, Symbol, and Narrative in the South

American Forest. Los Angeles: University of California Press, 1989.

-. Tejer y cantar. Caracas: Monte Ávila, 1990.

OLCA. 2013. Observatorio Latinoamericano de Conflictos Ambientales.

Disponible en http://www.olca.cl/oca/prensa/aliadasou.htm

Postone, Moishe. Time, Labor, and Social Domination. A Reinterpretation of

Marx's Critical Theory. Cambridge, UK: Cambridge University Press, 1993.

Viveiros de Castro, Eduardo. La mirada del jaguar. Introducción al perspectivismo

amerindio. Entrevistas. Buenos Aires: Eidiciones Tinta Limón, 2013. 